\title{
Management Design and Implementation of ISO9000 Serial Standards Based on Perceptual Quality of Mooc Videos
}

\author{
Zhong YANG \\ Anhui Broadcasting Movie and Television College, Broadcasting and Hosting Department, Hefei, China
}

\begin{abstract}
The emergence of Mooc brings a transmission from interpersonal communication to mass communication to the teachers, many of who cannot make use of the communication techniques before cameras. By virtue of the language expression methods of Chinese broadcasting science, we carry on the research and management controls of the perceptual quality of Mooc videos to set up the operation model of enhancing Mooc video quality by ISO9000 Serial Standards' management system.
\end{abstract}

KEYWORDS: Mooc; perceptual quality; Personal management; Programmed development

\section{INTRODUCTION}

The mass propagation force of Mooc (Massive Open Online Courses) draws a lot of enthusiasm of teachers to participate in the emerging teaching phenomenon. Moving the teaching process from the classroom to the network, education behavior actually has spread from interpersonal communication to public communication. Teaching from the classroom to Mooc video recording, the teachers have actually changed from natural person to media person. However, in Mooc video recording process, many new problems have come up. The teachers, who are used to standing in lecture platforms, tend to feel constrained in liquidity and appeal when faced up with camera lens because of the lack of perceptual interaction with students and teaching objects. In terms of the Mooc courses being launched in China now, the recording has presented the phenomenon of uneven perceptual qualities. The professor can perform vividly in classroom teaching, while video recording incurs a conversion problem to them in front of media. To help the teachers improve the transmission quality with the help of the professional skills of TV hosting, define the video recording skills of Mooc teachers, and to import IS09004-2 quality management concept in the process of video recording will open up a new research field. Although the traditional media does not conduct clear quality management on host appearance, as a network video product, the service objects of Mooc is featured with industrialization, popularization and individuation. Plus, the nonprofessionalism of video recording level of teachers all make it necessary to make a design of the whole process in accordance with the IS09000 quality standards, with the perceptual quality of Mooc videos as the object, as well as to improve teachers' video recording level by imitating the appearance skills of TV hosts, and then implement the perceptual quality management of videos according to IS09004-2 quality standards.

\section{GENERAL INSTRUCTIONS (HEADING 1)}

Perceptual quality exists in contrast with qualitative quality, which are possessed by all products at the same time. Take Mooc as a example, curriculum content of teachers, teaching ability and their academic level, etc are qualitative quality, and the teachers transmission charm in the video and the video making technique are the perceptual quality. It is the same as shopping, the etiquette, earnestness, swiftness and accuracy of the salesperson are the perceptual quality expected by customers. And it is the real quality of products that caters for the intangible expectation. However, for customers, both the tangible service and intangible service are important to them. Currently for Mooc, the perceptual quality of videos means the quality of video conversion from teachers' classroom teaching, which includes: teachers camera appearance manner, and the design of videos, research and development of video. The study of perceptual quality turns out to be more important owing to a variety of video styles and the high dropout rate of Mooc. 
3 PERCEPTUAL QUALITY MANAGEMENT OF INDIVIDUAL TEACHER IN VIDEO RECORDING

The private perceptual quality management of teachers in video recording is actually the behavior management before cameras. Vocal language expression is the final private quality goal of teachers. For teachers, what matters most is to learn to apply the language expression skills of Chinese broadcasting science rather than the drafts. The core of Chinese broadcasting science is the "three internals and four externals". Three internal techniques consist of scene reappearance, object sense and inner language, and the four external techniques consist of stop, accent, tone and rhythm. The role of para-language is certainly cannot be ignored, which includes expression, posture, and garments. As illustrated in Fig. 1.

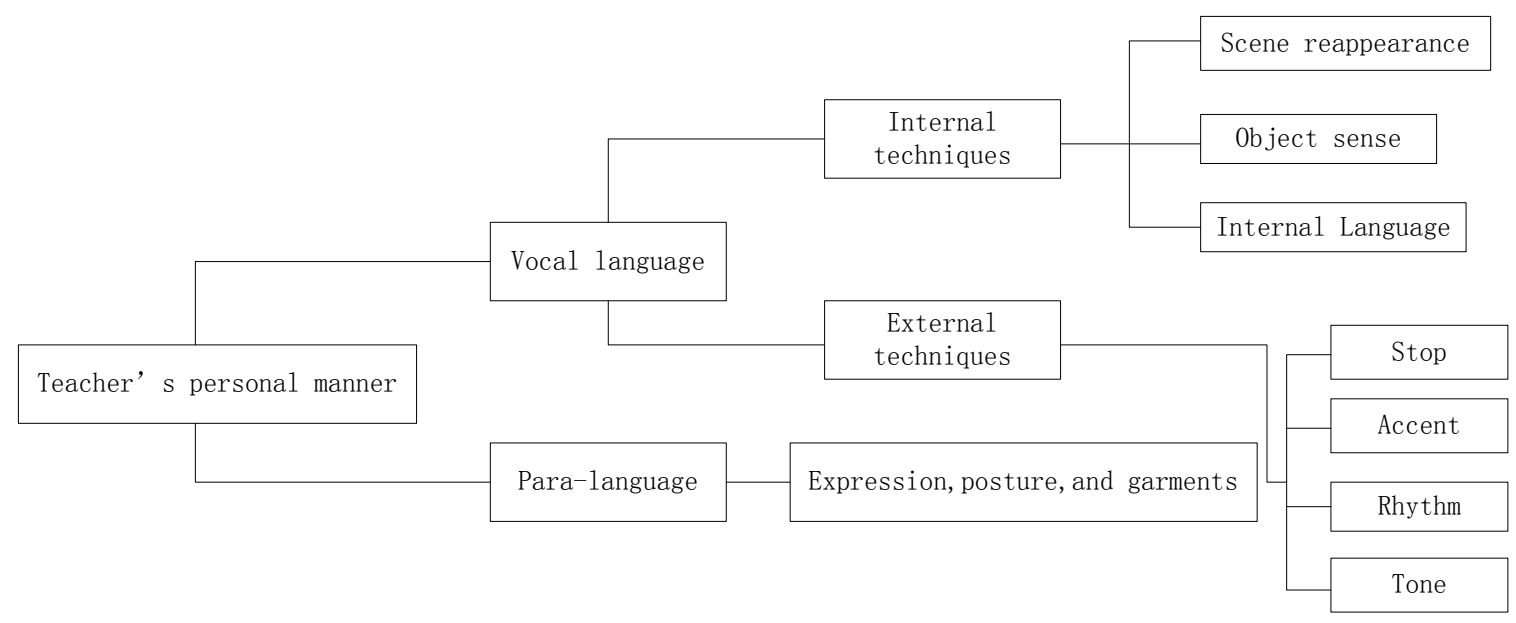

Fig. 1 Private perceptual quality system of teachers

Internal techniques are the movement skills of teachers' thoughts and feelings in the process of turning texts into vocal language. Scene reappearance is the constant flashing in mind of the emotion and scene in the manuscripts and it influences the broadcasting emotion by the stimulus of first signal system. Object scene is the authentically imaginary feel of the presence of students when teachers are confronted with the cameras, which can be imagined as students' knowledge-thirsting eyes; Inner language is the unexpressed statement nature and logical chain contained in the vocal language. These techniques exist in the teacher's mind, so they are called the inner techniques. External techniques refer to the skills that can be felt in the vocal language. Stop refers to the pause and connection of voice; Accent is the stressed character and word; Tone is a manner of speaking; Rhythm is the reciprocating movement of tone in the whole video. These aspects can act as a reference to measure teachers' personal perceptual quality. However, how to realize self-management of teachers? In accordance with the ISO9000 serial standards, the quality management of Mooc teaching video recording can be summarized as the following aspects: focusing on students, leadership before cameras, full participation, recording process management and control, recording system management and control, continuous improvement, decision-making system based on video recording, and interaction with platform. From the professional perspective of program recording by a TV host, the students are turn into the "customers" of Mooc video, and the Mooc teachers should put them in heart as if they did not see them, and they should respect, understanding, and rely on the students in the consideration of knowledge dissemination. And learn to highlight students' main body status by means of the TV hosting skills such as object sense, inner language and scene representation. The teachers tend to be flurried before a camera in the beginning, when brain is the "leader" of transmission system, and the organs like eyes, ears, nose, tongue and body become the "employees" of us. The imagination, sensibility and expressiveness of brain on manuscript and camera lens are key to achieving Mooc quality. The stop, accent, tone and rhythm of vocal language appeal a lot to the leadership effect of learners. To achieve the goals above requires a dedication of teachers in front of the cameras. Meanwhile, in the recording process, the Mooc teachers should be good at finding their potential values, and predict the potential of learners, fully mobilize their enthusiasm and creativity, think about the video quality, and control the quality of the video with full heart. In recording, it is the teachers and camera lens that make up the communication system, and in watching, it is the students and videos that make up the communication system. They need to give feedback to make improvement and interactive promotion in the two systems. Teachers are the subject of communication, while videos are the object of communication, and all decisionsmaking should be focused on the quality of videos. 
In addition, the students' feedback in network improve the quality of videos. System management interaction is also important information to further

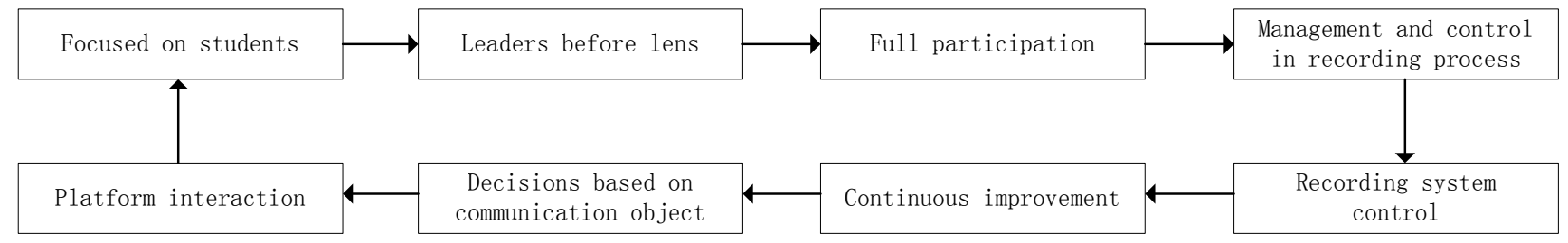

Fig. 2 Perceptual quality management system of Mooc video recording

\section{PROGRAMMED DEVELOPMENT OF MOOC VIDEOS}

The development and operation of a television program generally will go through marketing research, planning, copy writing, recording, editing, auditing, broadcast, etc. In the fierce market competition, the positioning and production of programs should be reviews elaborately, because the qualitative quality and perceptual quality of TV programs determine their ratings. The development of the Mooc videos has its own characteristics. The qualitative quality of education, that is the curriculum, determines the choice of the audience. Unlike the TV show, you can decide to watch it by its wonderfulness, the courses selected by a school is always for some reasons. Now on-line Mooc videos are mostly the works of some teachers in famous schools, who have high qualitative quality. In the future a large number of Mooc videos will be launched, but a lot of Mooc producers do not have studies on perceptual quality and they don't know how to improve it. But to the teachers without the broadcasting experience like announcers and hosts do, their individual weaknesses can be offset through the programmed developing of the curriculum, and this urgently need to be noticed by Mooc video. Combing with the ISO9004-2 Quality Management System and the producing process of TV program, we designed the service link of Mooc video recording. It is shown in Fig. 3.

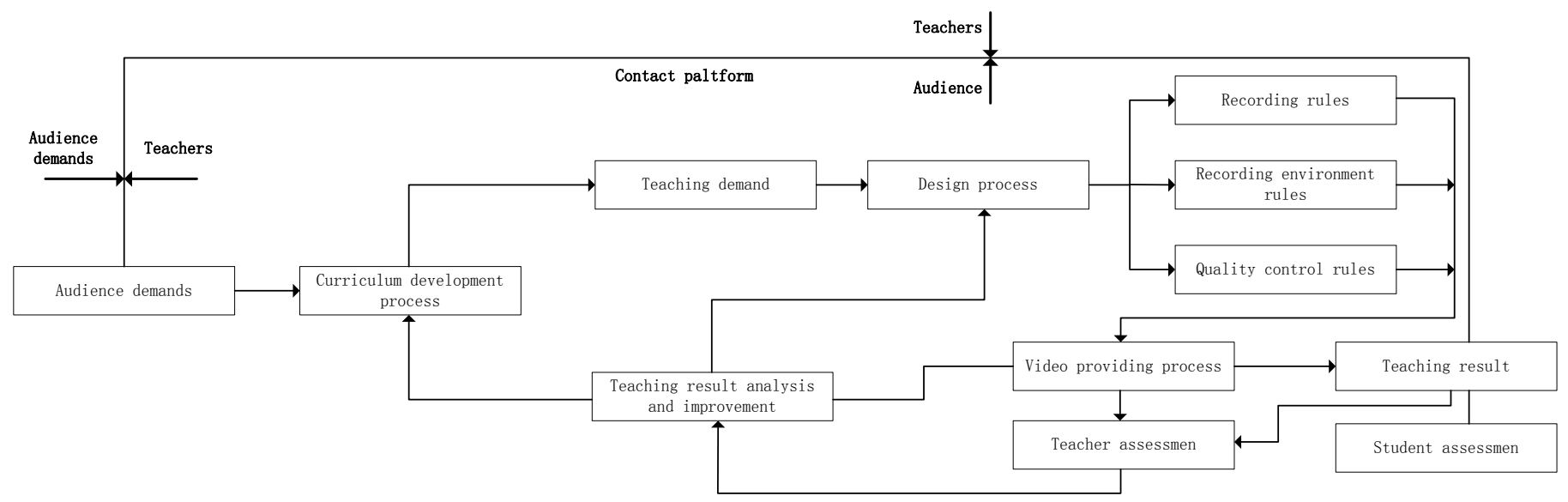

Fig.3 Service link of Mooc video recording

In order to record a Mooc course, the teachers first have to research the demands of market, and understand the needs of the audience. After a clear course orientation, the next step is curriculum development, which is not necessarily on the original traditional courses. It can be part of the original traditional courses, or a extraction of a field that meets the market needs, and even a new course development. Of course, the aim of the development is teaching demands.

After the curriculum fixed, it comes to the video recording process design. Firstly, it is the teaching step design and conception of $\mathrm{A} / \mathrm{V}$ performance, which are embodied in the conversion of text to vocal language. Every teacher has his/ her own strengths, and he/she should take more reference from the production planning of TV programs, adapt to the fragmentary recording which is different from the classroom teaching, and find the most suitable expression approach.

Secondly, a standard studio is necessary, of which the camera pixels, lighting arrangement and acoustical environment should be paid more attention to. Besides, the cooperation of recording person, the cameraman and lighting engineer are also important. This conversion is a challenge for the teachers at the first time, just like the first time on the platform for a new teacher. But they will adapt to 
it with the recording time going on, because this is the real "teaching platform" for a Mooc teacher. In some Mooc videos, the teachers only utter without video image, but the voice recording also needs to be done in a standard studio.

After the A/V material recording is completed, the next is clip synthesis. The editing process can hide and make up for the shortcomings. The finished clipping products may differ from the teaching plan, but all should take the teaching effect as the criterion. After the network videos are shown online, the audience will have a lot of feedback towards different roles, and this is the most comprehensive embodiment of the teaching result. The teachers at this point should summarize all feedback combining the students' evaluation, and then proceed to analysis and improve the teaching effect, and constantly alter the design, enrich the videos, and recyclably improve.

\section{THE SHORTCOMINGS OF MOOC VIDEOS IN IMPLEMENTING ISO9000 SERIAL STANDARDS}

(1) Copying the experience of enterprises will not pay off. Due to a shortage of experience in the early stage, the colleges often copy the practice of enterprises in production and management, which finally results in being "unable to acclimatize to local environment" of some teachers, and bad recording result. The reason for that is the bad fusion between each link.

(2) If the curriculum system and standards established by the teachers stray from the mass communication rules and actual situation, it is unable to performed or finished well. If the planning scheme does not fit well in the actual work, be it some advanced or too idealistic, it will lead to a hard execution. Too tight or strict standards are good for the enterprises that produce and possess products, but such a concept is kind of inappropriate in the teaching quality management of Mooc education.

(3) Despite that the schemes are completed, it is still difficult to execute them and the execution power can't keep up. First, the shooting institutions or the staff belongs to other departments, so their cooperation of video recording is not enough; second, a lack of supervision mechanism leads to the supervision out of place; third, the working time and effort of the video clip members cannot be guaranteed. More often, their work in clipping is merely a formality, so the intention of the teachers is not fully displayed.

(4) The feeling towards camera lens of teachers and their reappearance ability of text differ individually, which can only be enhanced by longterm training in front of the microphones. With the growing popularity of Mooc, only through a large number of video recording practices can the teachers have the opportunity to improve their abilities.

With the deepening impact of Internet on people's study and life, and the maturity of internationalization and marketization of Chinese higher education, the competition between Chinese universities and international schools is intensifying. The emergence of the Mooc will bring great convenience to many learners. In order to strive for the survival and development space, strengthening the operation management of Mooc and improving the education quality of Mooc will become the new problems faced by colleges and universities. Introducing ISO9000 serial standards, and establishing quality guarantee and monitoring system of Mooc video education are good methods worthy of learning. Despite the immaturity of them, and some parts still need further perfecting, Chinese mandarin broadcasting is a feature major in China. Linking it with Mooc teacher quality management is consistent with the characteristics of Chinese teachers and the present situation of the universities, and this research will effectively guarantee the enhancement of Mooc recording.

\section{ACKNOWLEDGEMENT}

In this paper, the research was sponsored by the 2014 anhui Colleges Quality Engineering massive open online courses (mooc) Demonstration projects (Project No. 2014mooc081).

\section{REFERENCES}

[1] Pu,L.C.1994. Zhu Lien Building and operation of service quality system-the implementation of ISO9004-2 standard, China metrology Press: 0721-0729, China: Beijing.

[2] He.J.S, Li.P.L, Guo.Z.L. 2000. Knowledge characteristic and hierarchical structure of GB/T9000 - ISO9000 serial standard, System engineering theory and practice.3 (3) 84 -88 .

[3] Zhao.X.C, Liu.H. 2013. University scientific research project management import, methodology research of IS09000 quality management system. Science and technology management research, 7(13) 124-127.

[4] Meng.Q.M. 2012. Research on university scientific research quality culture construction based on the standard of IS09000 .Value engineering 31 (26) : 247-248

[5] Han.F.R, Hao.J.2000. Comprehensive evaluation mode of quality management system effectiveness. Journal of Beijing industrial university.9 (20) 87-92.

[6] Run.Z.H. 2014. Reflections on a massive open online life cycle assessment course. Int $J$ Life Cycle Assess 19(14):1901-1907.

[7] Wulf.J, Blohm.I. 2014. Massive open online courses, Business \& Information Systems Engineering 2(14)111114.

[8] Song.Z. 2003. Broadcasting in China, Communication University of China Press, China: Beijing. 